\title{
Fecal glucocorticoid metabolites as an indicator of adrenocortical activity in Arctic foxes (Vulpes lagopus) and recommendations for future studies
}

\author{
Malin Larm ${ }^{1,2} \mathbb{D} \cdot$ Anne Lene Hovland ${ }^{3} \cdot$ Rupert Palme $^{4}\left(\mathbb{D} \cdot\right.$ Anne-Mathilde Thierry ${ }^{1} \cdot$ Andrea L. Miller $^{1} \cdot$ Arild Landa $^{5}$. \\ Anders Angerbjörn ${ }^{2} \cdot$ Nina E. Eide $^{1}$ (i)
}

Received: 27 March 2020 / Revised: 8 July 2021 / Accepted: 16 July 2021 / Published online: 15 August 2021

(c) The Author(s) 2021

\begin{abstract}
Measuring fecal glucocorticoid metabolites (fGCMs) is a widely used, non-invasive method for studies of stress in vertebrates. To study physiological responses in wild Arctic foxes (Vulpes lagopus) to perceived stressors such as fluctuating food availability, occurrence of competitors and predators and disturbance from human activities, a species-specific physiological validation of a method to evaluate adrenocortical activity is needed. Here we used 15 captive Arctic foxes (both males and females and juveniles and adults) to investigate fGCM concentrations following ACTH injection (physiological validation), or handling alone and compared them with their respective baseline concentrations prior to the treatments. A $5 \alpha$-pregnane-3ß,11ß,21-triol-20-one enzyme immunoassay measured significant fGCM increases following both treatments. The time lags to reach peak fGCM values were $9.3 \pm 1.3 \mathrm{~h}$ and $12.8 \pm 1.7 \mathrm{~h}$ for ACTH and handling treatment, respectively. Concentrations of fGCMs varied a lot between individuals, but not attributed to sex nor age of the foxes. However, we found a negative relationship between boldness and fGCM concentrations. Faecal glucocorticoid metabolites concentrations did not change significantly over a period of $48 \mathrm{~h}$ in samples kept at temperatures reflecting winter and summer means. This would allow the collection of samples up to two days old in the wild regardless of the season. We conclude that our successfully validated method for measuring fGCMs can be used as a non-invasive tool for studies exploring various stressors both in wild and captive Arctic foxes.
\end{abstract}

Keywords Arctic fox $\cdot$ Stress $\cdot$ Non-invasive method $\cdot$ Fecal glucocorticoid metabolites $\cdot$ ACTH challenge $\cdot$ Stability experiment

Malin Larm

malin.larm@zoologi.su.se

1 Norwegian Institute for Nature Research (NINA), Trondheim, Norway

2 Department of Zoology, Stockholm University, Stockholm, Sweden

3 Department of Animal and Aquacultural Sciences, Norwegian University of Life Sciences (NMBU), Aas, Norway

4 Department of Biomedical Sciences, University of Veterinary Medicine, Vienna, Austria

5 Norwegian Institute for Nature Research (NINA), Bergen, Norway

\section{Introduction}

The Arctic fox (Vulpes lagopus) has a circumpolar distribution and is considered in stable condition throughout most of its range (Audet et al. 2002), apart from Fennoscandia where the species has been threatened by extinction for more than 100 years (Angerbjörn et al. 2008; Henriksen and Hilmo 2015, but see also Tirronen et al. 2021). Throughout its range, Arctic foxes are subject to several potential stressors such as competition and predation from larger carnivores, marginal and highly fluctuating prey availability, as well as disturbance from humans. Similar to many other alpine and tundra species, they are also vulnerable to the warming climate and the impact of human land use, both of which has led to habitat loss, range expansion of the species' superior competitor, the red fox (Vulpes vulpes; Hersteinsson and Macdonald 1992; Killengreen et al. 2007; Elmhagen et al. 
2017), as well as reduction of the Arctic fox's most important prey species; the lemmings (Lemmus lemmus; Ims et al. 2008; Kausrud et al. 2008). These stressors are likely most pronounced in the edges of the Arctic fox's natural distribution, such as in Fennoscandia, however, these stressors are also emerging in the continuous tundra populations (see e.g. Sokolov et al. 2016; Gallant et al. 2019).

In Fennoscandia, intensive conservation measures, such as supplemental feeding, culling of red foxes and release of captive born Arctic foxes, are carried out in several of the few remaining subpopulations, with the goal to increase Arctic fox numbers to viable levels (Angerbjörn et al. 2013; Eide et al. 2017; Ims et al. 2017; Landa et al. 2017). An understanding of all threats is important when conservation actions are planned. Therefore, research projects targeting different aspects of the Arctic fox ecology and conservation are conducted, among them studies of behavioral responses to tourism activity (Larm et al. 2018, 2020a, b). Still, even though behavioral responses function as important indicators of animals' status and welfare, they may not fully reflect the disturbance caused to an animal and can be misinterpreted (Gill et al. 2001; Le Corre et al. 2009). Furthermore, physiological stress responses may also occur before behavioral signs of stress are displayed and are more likely to objectively reflect disturbance effects. Therefore, studies of physiological stress responses could be a valuable complement to behavioral studies (Giese 1998; Villiers et al. 2005). Minimizing stress is also important in a captive breeding situation, not only to maximize animal health and welfare but also to ensure the success of reproduction (Mason 2010). Particularly for the Norwegian Arctic fox captive breeding and release program, the ability to measure physiological stress responses could be used, for example, to assess the relationship between newly paired individuals, to examine reactions to disturbances around the station, and to evaluate response to handling and transport. Developing methods to evaluate physiological stress responses could therefore be a valuable tool for studying effects of different stressors on Arctic foxes both in wild and captivity, across the species' distribution range.

When an animal perceives aversive stimuli in their environment (stressors), adrenocorticotropic hormone (ACTH) is released from the pituitary gland, which in turn stimulates the adrenal cortex to then release glucocorticoids (GCs; cortisol and/or corticosterone). Glucocorticoids induce a range of behavioral and physiological responses, such as energy mobilization and increased vigilance, enabling individuals to cope with the environmental stressor (Möstl and Palme 2002; Reeder and Kramer 2005). Although monitoring GC concentrations is not synonymous for stress (MacDougallShackleton et al. 2019), their measurement is widely used as a parameter for adrenocortical activity. Glucocorticoids can be measured in several different tissues, including blood, saliva, urine, hair, and feces. The invasiveness of the sampling methods varies as does the time scale for the measured GC concentrations (Sheriff et al. 2011a). For instance, blood sampling is an invasive sampling technique which provides a nearly instantaneous measure of adrenocortical activity, while hair sampling is a less invasive sampling technique which provides a measure of adrenocortical activity over a long time. For both hair and blood, adrenocortical activity is measured by quantifying the GCs themselves. However, in feces, adrenocortical activity is measured by quantifying the glucocorticoid metabolites (fecal glucocorticoid metabolites (fGCMs)) that are being excreted from the body. Fecal glucocorticoid metabolites can be measured as an integrated measure of adrenocortical activity and represent the cumulative secretion of hormones (usually over several hours dependent on defecation rate, Palme et al. 2005; Sheriff et al. 2011b). Fecal glucocorticoid metabolite levels appear particularly interesting as a measure of adrenocortical activity of wild animals, because fecal samples can be easily and non-invasively collected in the field without need for capture and handling (Sheriff et al. 2011a; Palme 2019). It is also possible to sample the same individual repeatedly with minimal risk of affecting the GC responses (Touma and Palme 2005; Palme 2019). The use of fGCMs has been validated as an indicator of adrenocortical activity in carnivores (e.g. Monfort et al. 1998; Schatz and Palme 2001; Young et al. 2004; Malmkvist et al. 2011), and specifically in several fox species, including the silver fox (Vulpes vulpes; Hovland et al. 2017), bat-eared fox (Otocyon megalotis; le Roux et al. 2016), island fox (Urocyon littoralis; Kozlowski et al. 2020) and the crab-eating fox (Cerdocyoun thous; Paz et al. 2014). Because of significant differences between species in excreted fGCMs (Palme 2019) and in gut passage time, it is necessary to validate FGM measures for each species and assay. Although fecal GCMs have recently been used in studies of stress in both wild (McDonald et al. 2018) and farmed Arctic foxes (Sanson et al. 2005), no successful validation of the method was carried out in these studies. A physiological validation is an experimental process, where animals are injected with synthetic ACTH, thereby stimulating the release of glucocorticoids (Touma and Palme 2005). Fecal samples are then collected over a defined time period following the injection and are analyzed for fGCMs. The results of these analyses are used to determine which enzyme immunoassay (EIA) best detects the increase in fGCM concentrations, and thus is best suited for future studies. A control treatment to test for the effect of the handling procedure itself is also recommended (Palme 2019). When collecting feces from wild animals in the field it is important to consider that fGCM concentrations may change over time and at different rates in relation to, for instance, temperature and weather conditions (Millspaugh and Washburn 2004). As a complement to the validation, it is therefore 
also recommended to perform a fGCM stability experiment for the given species, method and expected environmental conditions (Palme et al. 2013; Palme 2019).

Adrenocortical activity often has diurnal and seasonal fluctuations and may vary between individuals as a result of such factors as sex, age, breeding status, personality traits, previous experiences, and social interactions (e.g. for a review see: Palme 2019; Sosa et al. 2020; Steinman \& Robeck 2021). Individual variation in personality traits can be related to differences in reactions to stressors. Variations in personality can be viewed along a proactive-reactive continuum, where proactive (bold, explorative and social) individuals generally are expected to have lower stress reactions and thus a lower secretion of glucocorticoids following a stressor, compared to more reactive (shy, less explorative and less social) individuals (Koolhaas et al. 1999; Carere et al. 2010). Following previous experiences of a stressor, animals may also habituate, i.e. increase their tolerance towards the stressor, as they learn not to perceive it as a threat, which thereby leads to a reduction in the adrenocortical activity and GC secretion (Shutt et al. 2014). Analyses to test for a possible diurnal rhythm and personality differences in excreted fGCM concentrations are therefore valuable as a complement to the validation (Palme 2019).

The aim of this study was to validate the use of an EIA for measuring fGCMs as an indicator of adrenocortical activity in Arctic foxes. This test could then be used in future studies assessing the responses of wild Arctic foxes towards stressors such as human disturbance from tourism, presence of predators or competitors, and changes in food availability. It can also be used as a tool to optimize the health/welfare and reproduction of Arctic foxes within the captive breeding and release program. We investigated fGCM concentrations following ACTH injection (physiological validation) and handling alone and compared them with respective baseline concentrations prior to the treatments. We also examined the relationship between fGCM concentrations and individual variations in boldness and confidence toward humans derived from behavioral test performed in connection with the validation experiment and tested for potential diurnal variations. Finally, because fecal samples may not be collected directly after defecation in the wild, we performed a stability experiment to study how fGCM concentrations changed over time at different temperatures.

\section{Methods}

\section{Animals and housing}

As the Arctic fox is considered endangered in Fennoscandia, it was not possible to use wild foxes for the validation experiment. We therefore used farmed Arctic foxes of the «white polar morph», a less common recessive color mutation of the farmed blue Arctic fox. Blue foxes are bred for rapid growth and large body size (e.g. Kempe et al. 2009). Whereas the blue fox may experience leg problems (bent feet) and moving difficulties, the «white polar» foxes are smaller in size and appear more agile compared to the standard blue foxes. The experiment took place at a fur farm in the Byneset municipality just east of Trondheim, Norway, where the foxes were born and reared. It was conducted during winter, between December 21st 2018 and January 23rd 2019, with temperatures around $0{ }^{\circ} \mathrm{C}$ or lower throughout the study period. A total of 16 foxes were initially included in the experiment, of which 7 were juvenile females (6-7 months old, $6.8 \pm 0.75 \mathrm{~kg}), 6$ juvenile males $(6-7$ months old, $7.9 \pm 0.12 \mathrm{~kg}$ ), and 3 adult females ( $>36$ months old, $8.1 \pm 0.65 \mathrm{~kg}$ ). The foxes were housed in an outdoor barn open to natural light and temperatures in individual wire mesh cages containing a wire mesh shelf, an automated water drinking nipple, and a wooden stick for enrichment (following the regulations on the keeping of fur animals in Pelsdyrforskriften FOR-2011-03-17-296). They were fed once a day in the morning with equal amounts of standard food paste for fur animals. The study was reviewed by the Norwegian Institute for Nature Research's animal welfare unit and approved by the Norwegian Food Safety Authority (Mattilsynet, FOTS identity no. 18734).

\section{Experimental procedure and collection of feces}

Foxes were weighed and moved to one barn in cages next to each other along two parallel rows 14 days prior to the first sampling to allow for habituation. The housing order of the three fox groups was random and the foxes were handled in consecutive housing order. To collect the feces, single sheets of hessian fabric were placed under the cages for the feces to fall on. The sheets were placed individually under each cage to prevent cross contamination. Due to the cold conditions during the experiment period, feces were frozen directly after defecation. Two treatments were performed during the experiment, one for the physiological validation, where synthetic ACTH was injected and the other a control treatment where the foxes were handled only (no injection). Fecal samples were collected during four 24 -h periods, one for each treatment and one baseline sampling that preceded each treatment (Timeline in Fig. 1). All feces were collected in plastic bags and immediately stored at $-20{ }^{\circ} \mathrm{C}$. There were almost always several fecal droppings collected during each sampling interval. All feces collected under one cage were put in the same bag and then homogenized for the analysis.

Sampling for baseline evaluations began at 12:00 and feces were collected every fourth hour thereafter over $24 \mathrm{~h}$ for a total of six sampling intervals $(00-04 \mathrm{~h}, 04-08 \mathrm{~h}$, 


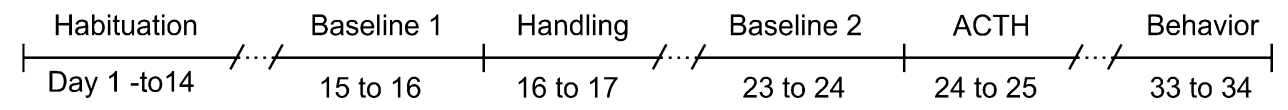

Fig. 1 Timeline of the experiment. Fecal samples were collected during 'Baseline 1', 'Handling', 'Baseline 2' and 'ACTH'. During 'Behavior' the novel object and tit bit tests were performed

08-12 h, 12-16 h, 16-20 h, 20-24 h). Both treatments were performed in the morning following baseline collections (between 08:00 and 09:30) after which fecal sample collection started at 12:00 and followed the same schedule as the baseline samplings. The handling and ACTH challenge treatments were performed eight days apart to avoid any carry-over effects. During the handling treatment, the foxes were captured and held outside of the cage. The total procedure lasted for 2 min per fox and was completed within 40 min for all foxes (08:00-08:40). For the ACTH treatment, foxes were captured and held outside of the cage for an intramuscular injection of $1 \mathrm{ml}$ of $0.25 \mathrm{mg} \mathrm{ml}^{-1}$ tetracosactide hexaacetate (Synacthen ${ }^{\circledR}$, Alfasigma, Milan, Italy) in the upper left thigh (M. semitendinosus). The ACTH injection was done by a veterinarian, and was completed for all foxes within approximately $15 \mathrm{~min}$ (09:14-09:26 am).

\section{Analysis of fecal glucocorticoid metabolites (fGCMs)}

Before preparation, all fecal samples were frozen at $-80{ }^{\circ} \mathrm{C}$ for a minimum of $48 \mathrm{~h}$, to kill potential parasites (e.g. Echinococcus spp.). The samples were thawed at room temperature for approximately $1 \mathrm{~h}$ and then homogenized inside the plastic bags prior to the extraction. The farmed foxes had wooden sticks to chew on in each cage and as a consequence wooden parts were sometimes found in the feces. These were removed. From each sample, $0.5 \mathrm{~g}$ of feces was weighed into a glass tube and extracted with $5 \mathrm{ml} 80 \%$ methanol. Feces and methanol were mixed for $30 \mathrm{~s}$ using a hand vortex followed by 30 min using a multi vortex. The samples were then centrifuged at $850 \mathrm{~g}$ for $15 \mathrm{~min}$, after which a $0.5 \mathrm{ml}$ aliquot of the supernatant was pipetted into $1.5 \mathrm{ml}$ Eppendorf tubes (Palme et al. 2013) and stored at $-20{ }^{\circ} \mathrm{C}$ before being sent on dry ice to the University of Veterinary Medicine in Vienna. There extracts were further diluted in assay buffer $(1+9)$, before EIA analysis. A suitable EIA was identified based on 35 fecal samples from 6 different foxes ( 3 females and 3 males) collected during the ACTH treatment. A cortisol immunoassay (Palme and Möstl 1997) was tested, but did not show the expected increases in fGCM concentrations. Instead, a $5 \alpha$-pregnane-3ß,11ß,21-triol-20one EIA (for details of the EIA, including cross-reactions see Touma et al. 2003) was found suitable for the Arctic fox. Therefore, all samples were analysed with this EIA. Intraand inter-assay coefficients of variation of high and low concentration pools were all below $10 \%$ and $15 \%$, respectively.
Reverse-phase high performance liquid chromatography (HPLC) separations were performed for all three groups of foxes separately to characterize the measured metabolites (for details see: Touma et al. 2003). The time to reach peak fGCM concentration was determined for each fox based on the sample with the highest concentration within $24 \mathrm{~h}$ of the treatment.

\section{Storage experiment}

To study the stability of the fGCMs under various temperatures, a storage experiment was carried out on 10 fecal samples collected between treatment samplings. The samples were frozen after collection and then treated according to the protocol above. From each sample, 9 glass tubes with a $0.5 \mathrm{~g}$ subsample were prepared. One subsample was extracted at the start of the experiment, while the remaining subsamples were stored either at $8-10{ }^{\circ} \mathrm{C}$ or at $20^{\circ} \mathrm{C}$ for $6 \mathrm{~h}, 12 \mathrm{~h}, 24 \mathrm{~h}$ or $48 \mathrm{~h}$ before extraction. The temperatures were chosen to reflect the mean temperature of tundra environments during July and August (approx. $6-12{ }^{\circ} \mathrm{C}$; SMHI 2020) and temporary high day temperatures (up to $20-25^{\circ} \mathrm{C}$ ).

\section{Behavioral assessments—-tit bit and novel object}

Two different behavioral tests, "tit bit" and "novel object", were performed directly following the validation experiment in order to investigate a potential relationship between behavior and fGCM concentrations before (baseline) and after handling. The "tit bit" test reflects the fearfulness of the fox towards the human observer (Rekilä et al. 1997) and was used by Hovland et al. (2017) to assess confidence towards humans in the silver fox in a fGCM study with a similar experimental design as our study. Following the protocol outlined by Rekilä et al. (1997), the foxes were offered a small piece of food (Frolic ${ }^{\circledR}$, dog food) from the hand of the observer through the wire mesh cage for $30 \mathrm{~s}$. It was noted whether the fox took the food or not. The experiment was repeated for 5 consecutive rounds during the same day. An average score of the 5 trials for each fox was calculated for whether it took the food or not $(0=$ did not take food, $0.5=$ smelled food, $1=$ took food). A higher score indicated an individual more confident with human interaction. Responses to novel objects have in several previous studies been linked to boldness/shyness (Réale et al. 2007; Haage et al. 2013; Andersson et al. 2014). In the "novel object" test, the foxes were presented with a novel object (a stone duck) in 
the cage for $5 \mathrm{~min}$. Every $10 \mathrm{~s}$ we recorded whether the fox interacted with the object (sniffing, biting, scrabbling, moving or marking). From the 10 s-observation scores, the portion of the 5 min that each fox was in contact with the object was calculated. A higher score indicated a bolder individual.

\section{Statistical analyses}

Concentrations of fGCMs were log-transformed to achieve a normal distribution for the linear models. One juvenile female was excluded from the analyses as she ate poorly and defecated markedly less than the other foxes, which could have resulted in potentially biased values. The effect of the handling and ACTH challenge treatments on FGCM concentrations were tested separately using linear mixed effect models (LME4 package, Bates et al. 2015) with 'Treatment' (Handling-Baseline and ACTH challenge-Baseline), 'Group' (Juvenile female, Juvenile male, Adult female) and 'Interval' (Fecal sampling interval: 1-6) and all two-way interactions between them as fixed effects. 'Fox ID', 'Handling order' and the interaction terms 'Fox ID:Treatment' and 'Fox ID:Interval' were included as random effects. The emmeans package (Lenth et al. 2019) was used for post hoc pairwise comparisons. Peak fGCM concentrations following the handling and the ACTH challenge treatments were compared with a paired t-test. Between-group comparisons of peak fGCM concentrations and time to reach peak concentrations following each treatment as well as the boldness $(0-1)$ and confidence $(0-1)$ scores were performed with oneway ANOVAs. Diurnal variation in baseline fGCM concentration was analyzed using an ANOVA with 'Group' and 'Interval' as explanatory variables. To study the relationship between behavior and fGCM responses, the boldness and confidence scores were correlated against the mean concentrations prior to (baseline) and following handling as well as peak concentrations and time to reach peak concentrations following handling. To test for any effects of handling order on boldness and confidence scores, they were also correlated against handling order. Separate linear models were fitted for the temperatures $\left(8-10^{\circ} \mathrm{C}\right.$ and $\left.20^{\circ} \mathrm{C}\right)$ in the storage experiment, with fGCM concentration as the response variable and 'Time' $(0-48 \mathrm{~h})$ as the explanatory variable. All analyses were performed using R (R Core Team 2019), RStudio version 1.2.5033 (R Studio 2019).

\section{Results}

\section{Physiological validation-ACTH challenge treatment}

Following the ACTH challenge treatment, fGCM concentrations increased for each of the fifteen foxes and the mean
fGCM concentrations differed significantly from the baseline concentrations during fecal sampling intervals $1-5(0-20 \mathrm{~h})$, but not during interval 6 (20-24 h; Treatment:Interval interaction: $F_{5,61.81}=9.75, p<0.0001$, Fig. 2$)$. Average ( \pm SE) peak fGCM concentrations following ACTH injection were $2414 \pm 264 \mathrm{ng} \mathrm{g}^{-1}(n=15)$, baseline fGCM concentrations were $695 \pm 79 \mathrm{ng} \mathrm{g}^{-1}(n=15)$ and the time to reach peak concentration was $9.3 \pm 1.3 \mathrm{~h}(n=15)$. There were no differences between the groups (female adults, female juveniles and male juveniles), neither in peak fGCM concentration $\left(F_{2,12}=0.94, p=0.4167\right)$ nor in the time to reach peak concentration $\left(F_{2,12}=0.51, p=0.6138\right)$.
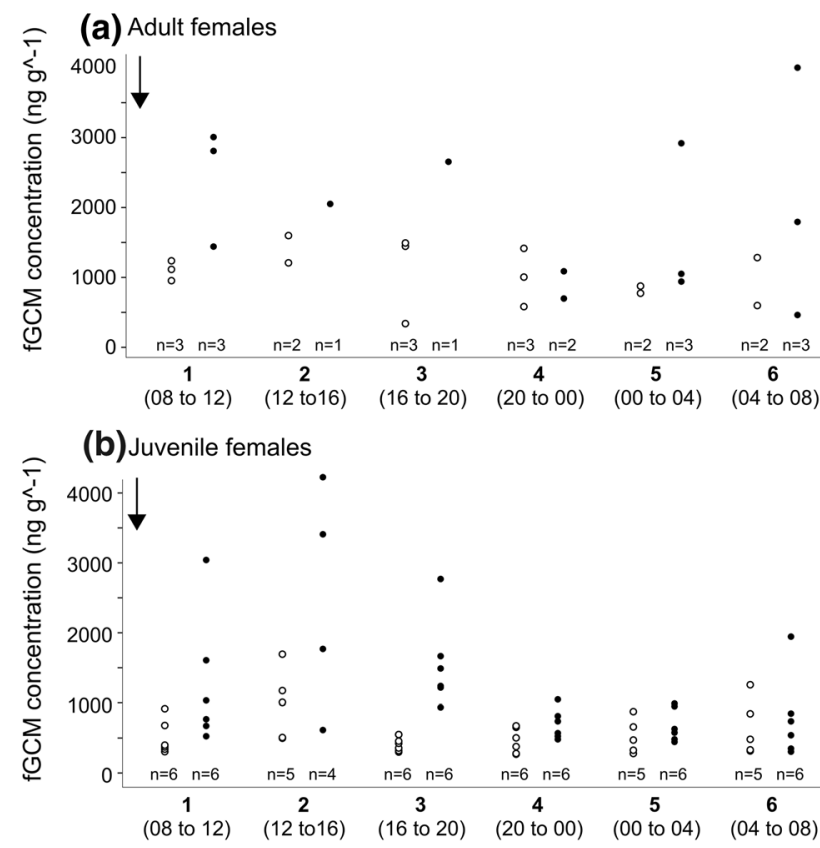

(c) Juvenile males

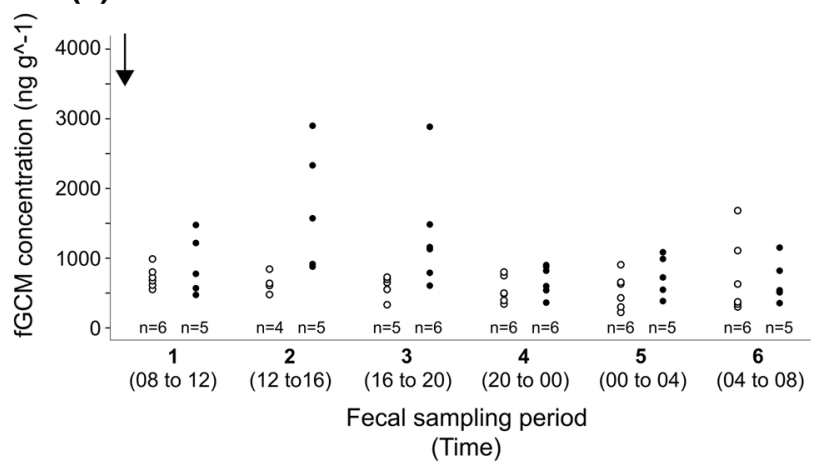

Fig. 2 Fecal glucocorticoid metabolite (fGCM) concentrations in adult female (a), juvenile female (b) and juvenile male (c) Arctic foxes (Vulpes lagopus) following the ACTH challenge treatment (black dots) compared to respective baseline concentrations before the ACTH challenge treatment (white dots). The ACTH treatment was performed in the morning (indicated by arrow) and samples were collected every fourth hour for $24 \mathrm{~h}$ (Fecal sampling interval: 1-6) before (baseline sampling) and after (ACTH sampling) the treatment 


\section{Handling treatment}

Following the handling treatment, mean fGCM concentrations were significantly increased compared to the baseline during fecal sampling interval 3-4 (8-16 h), but not during interval 1-2 $(0-8 \mathrm{~h})$ or interval 5-6 (16-24 h; Treatment:Interval interaction: $F_{5,59.11}=2.46, p=0.04361$, Fig. 3). Average ( $\pm \mathrm{SE}$ ) peak fGCM concentrations following handling were $1856 \pm 342 \mathrm{ng} \mathrm{g}^{-1}(n=15)$, baseline fGCM concentrations were $988 \pm 117 \mathrm{ng} \mathrm{g}^{-1}(n=15)$ and the time to reach them was $12.8 \pm 1.7 \mathrm{~h}(n=15)$. There were no differences between groups, neither in peak fGCM concentrations $\left(F_{2,12}=2.09, p=0.1664\right)$ nor in the time to reach them $\left(F_{2,12}=0.2, p=0.8214\right)$. Peak fGCM concentrations following the ACTH treatment were higher than after the handling treatment $\left(t_{14}=2.45, p=0.0279\right)$ and the effect also lasted longer following the ACTH challenge (significant effect 0-20 $\mathrm{h}$ after the treatment) than for the handling test (significant effect $8-16 \mathrm{~h}$ after treatment). There was a significant diurnal variation in the baseline fGCM concentrations, indicating a higher adrenocortical activity during the night (both baselines included, $F_{5,334}=7.3, p<0.0001$ ).

\section{High-performance liquid chromatography (HPLC)}

The HPLC immunograms revealed that higher immunoreactivity was detected by the $5 \alpha$-pregnane-3ß,11ß,21-triol-20one EIA compared to the cortisol EIA. Cortisol itself was absent, and no sex and only minor age differences in formed metabolites were found (Fig. 4).

\section{Storage experiment}

In the storage experiment, we found no significant changes in fGCM concentrations over the 48-h period, neither for the samples stored at $8-10^{\circ} \mathrm{C}\left(n=10, r^{2}=-0.003, F=0.87\right.$, $p=0.3560)$, nor for those kept at $20{ }^{\circ} \mathrm{C}(n=10, \mathrm{r} 2=0.04$, $F=2.88, p=0.0958$; Fig. 5a). Maximal change in fGCM concentrations expressed as percent change from $t=0$ for each temperature regime is shown in Fig. 5b.

\section{Fecal glucocorticoid metabolite concentrations related to boldness and confidence scores}

The mean boldness score (0-1), derived from the "novel object" test, varied between groups $\left(F_{2,12}=5.0, p=0.0268\right)$. Juvenile females were found to be the boldest group $(0.7 \pm 0.1, n=6)$ followed by juvenile males $(0.5 \pm 0.1, n=6)$ and adult females $(0.1 \pm 0.2, n=3)$. The difference between adult female and juvenile female scores was significant $(p=0.0221)$, but there was no significant difference between the juvenile male scores and juvenile females $(p=0.2631)$ or juvenile males and adult females $(p=0.2182)$. There was
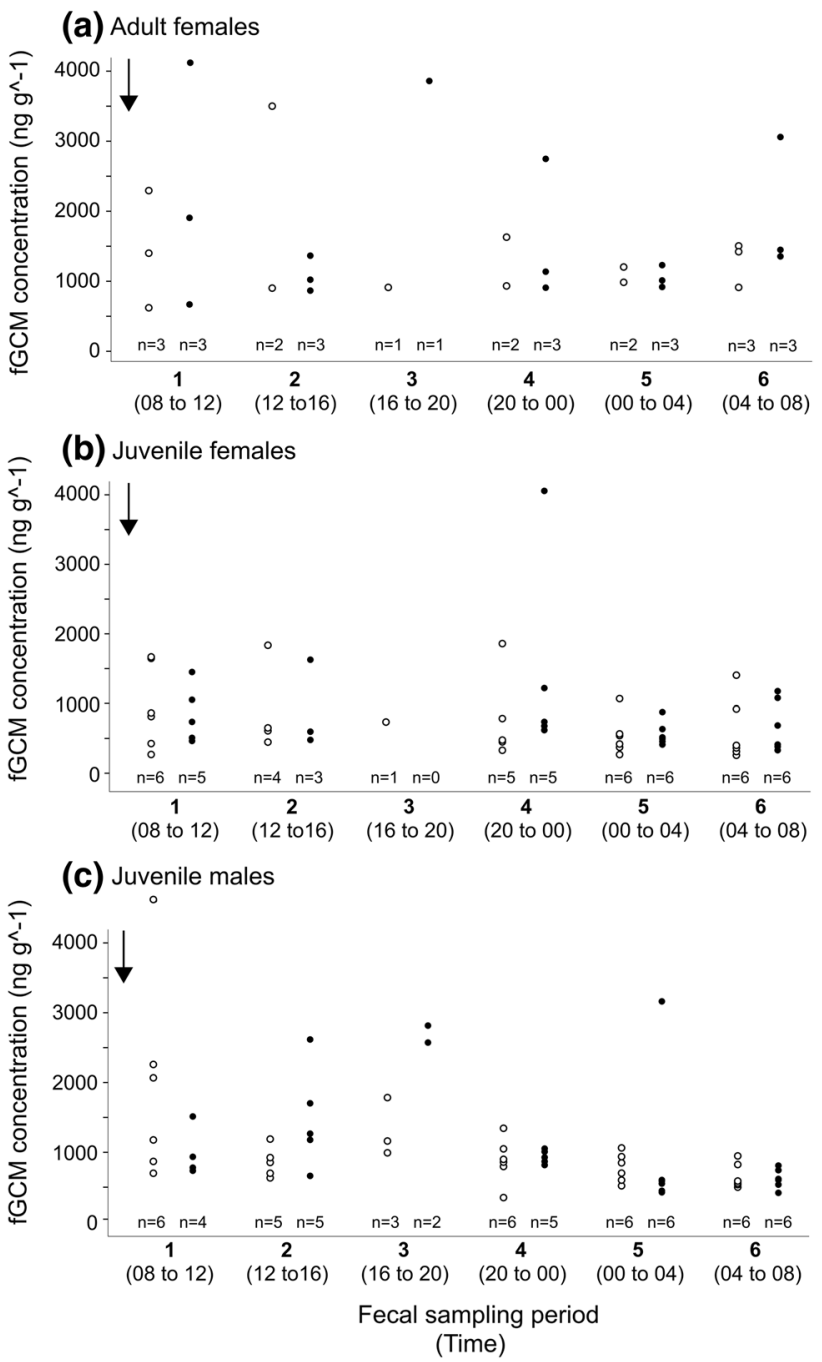

Fig. 3 Fecal glucocorticoid metabolite (fGCM) concentrations in adult female (a), juvenile female (b) and juvenile male (c) Arctic foxes (Vulpes lagopus) following the handling treatment (black dots) compared to baseline concentrations before the handling treatment (white dots). The handling treatment was performed in the morning (indicated by arrow) and samples were collected every fourth hour for $24 \mathrm{~h}$ (Fecal sampling interval: 1-6) before (baseline sampling) and after (handling sampling) the treatment

also some variation between groups in the mean confidence score (0-1) derived from the "tit bit" tests, where juvenile females $(0.9 \pm 0.2, n=6)$ were most confident, followed by juvenile males $(0.3 \pm 0.2 n=6)$ and adult females $(0.2 \pm 0.2$ $n=3)$. The differences were not, however, statistically significant $\left(F_{2,12}=3.68, p=0.0566\right)$. The boldness and confidence scores tended to be significantly correlated $\left(r_{13}=0.48\right.$, $p=0.06912$ ), which suggests that the two behavioral measures could consistently describe individual personality differences in the foxes. No effects of handling order were found on either boldness $\left(r_{13}=0.08, p=0.7880\right)$ or confidence scores $\left(r_{13}=-0.24, p=0.3788\right)$. 
Fig. 4 High-performance liquid chromatography (HPLC) immunograms for adult female (a), juvenile female (b) and juvenile male (c) Arctic foxes (Vulpes lagopus). Higher immunoreactivity was detected by the $5 \alpha$-pregnane- $3 \beta, 11 \beta, 21$ triol-20-one EIA (solid line, left $y$-axes) compared to the cortisol EIA (dotted line, right y-axes), which did not differ between the three groups. The elution times of the estradiol disulphate $\left(\mathrm{E}_{2}\right.$-diSO $\left.\mathrm{d}_{4}\right)$, estrone glucuronide $\left(E_{1} G\right)$, estrone sulfate $\left(E_{1} S\right)$, cortisol and corticosterone standards are indicated by the open triangles (a) Adult female

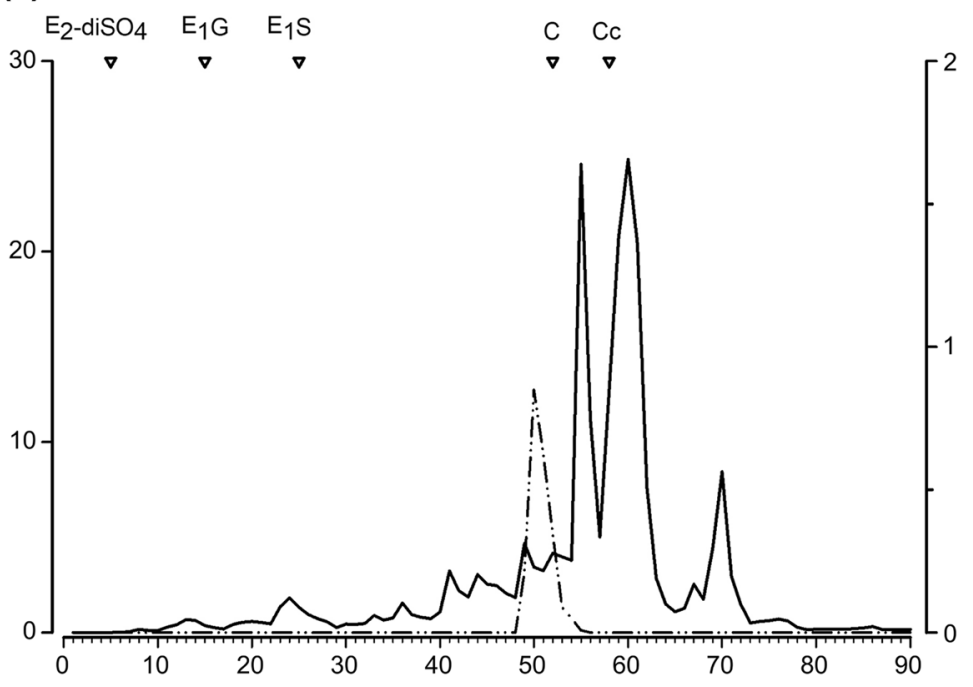

(b) Juvenile female

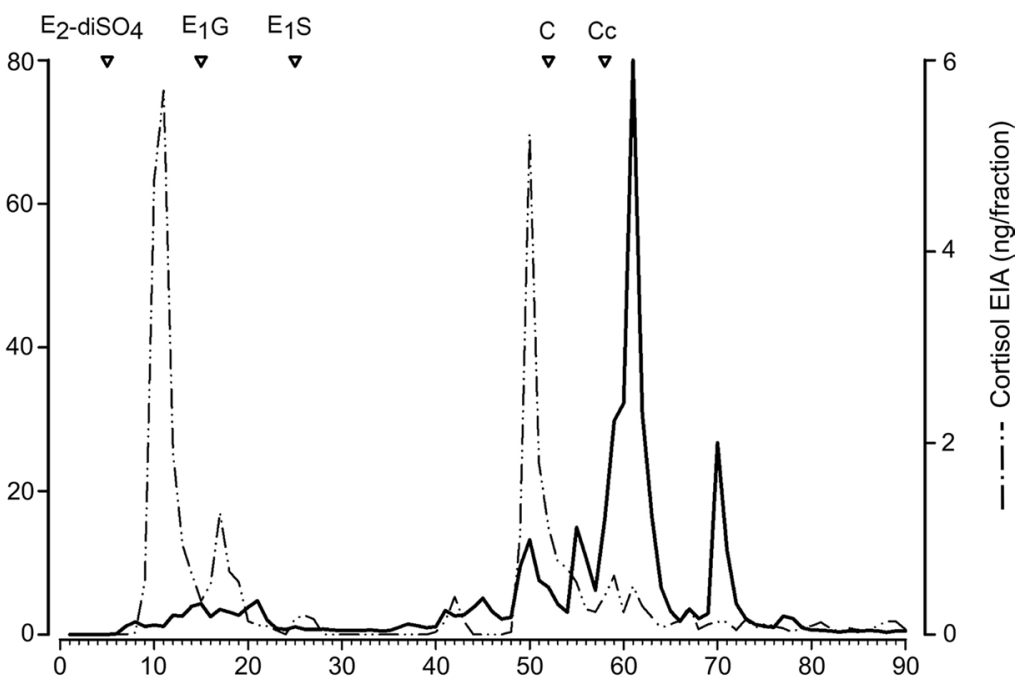

(c) Juvenile male

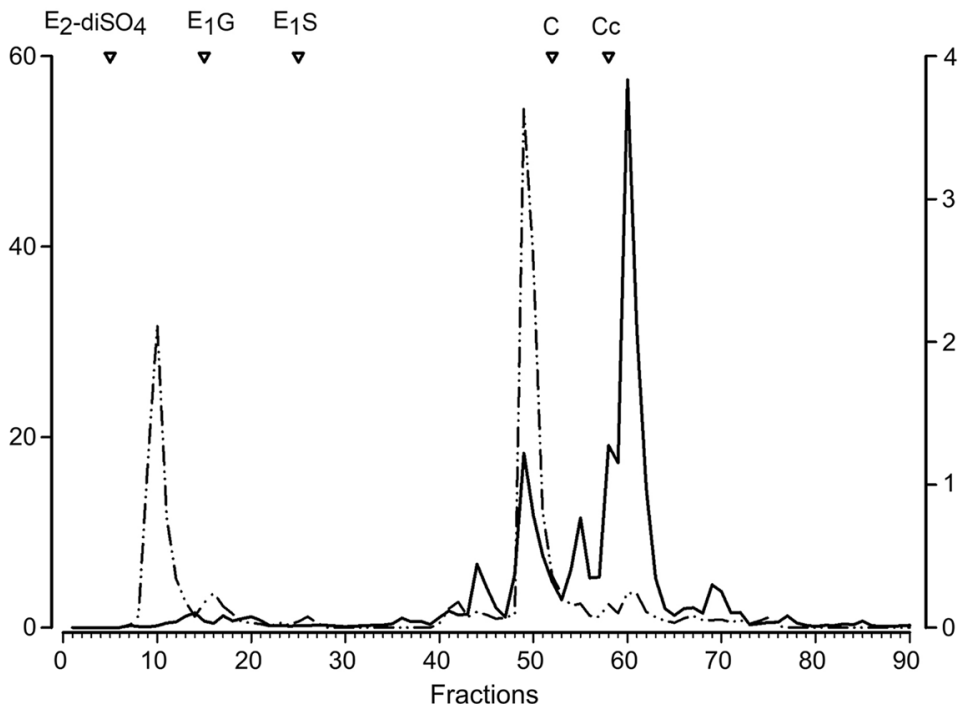




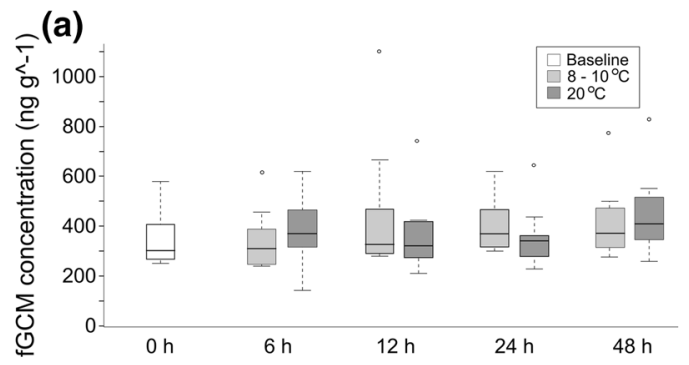

(b)

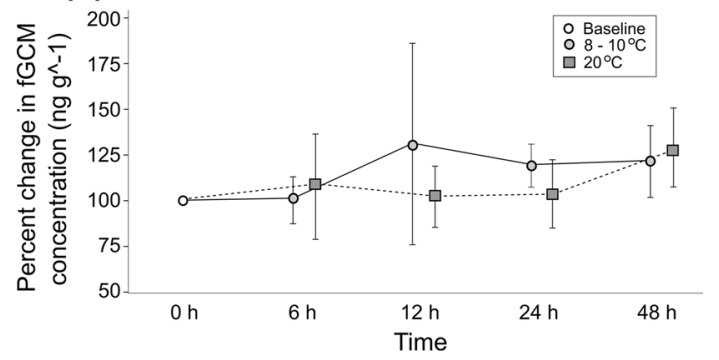

Fig. 5 Boxplots of absolute (a) and relative (b, expressed as percent change from $\mathrm{t}=0$ ) fecal glucocorticoid metabolite (fGCM) concentrations for each temperature regime in samples $(n=10)$, stored for up to $48 \mathrm{~h}$ at $8-10{ }^{\circ} \mathrm{C}$ (light grey) or $20^{\circ} \mathrm{C}$ (dark grey) compared to fresh samples $(0 \mathrm{~h}$; white)

The boldness score was negatively related to mean baseline fGCM concentrations during the $24 \mathrm{~h}$ before handling $\left(r_{13}=-0.58, p=0.0235\right.$, Fig. 6$)$ and tended also to be negatively related to the mean concentrations during the $24 \mathrm{~h}$ following the handling $\left(r_{13}=-0.47, p=0.0744\right.$, Fig. 6$)$. The increase in mean concentrations from baseline to handling did, however, not vary with boldness score $\left(r_{13}=-0.11\right.$, $p=0.7040)$. The boldness score was not related to the peak fGCM concentrations $\left(r_{13}=-0.38, p=0.1595\right)$ or time to reach peak concentrations following handling $\left(r_{13}=0.39\right.$, $p=0.1481$, Fig. 6).

There was no correlation between confidence score and mean baseline fGCM concentrations before handling $\left(r_{13}=-0.13, p=0.6315\right.$, Online Resource 1$)$, mean concentrations after handling $\left(r_{13}=-0.06, p=0.8396\right.$, Online Resource 1), peak concentrations $\left(r_{13}=-0.07, p=0.7981\right)$ or time to reach peak concentrations $\left(r_{13}=-0.05, p=0.8537\right.$, Online Resource 1) after handling.

\section{Discussion}

The aim of this study was to validate an EIA for measuring fecal glucocorticoid metabolite (fGCM) concentrations as an indicator of adrenocortical activity in Arctic foxes, with the ultimate goal to use these results to study stress responses in both wild and captive-bred Arctic foxes. A 5 $\alpha$-pregnane-3B, 11ß,21-triol-20-one EIA (Touma et al. 2003) proved well
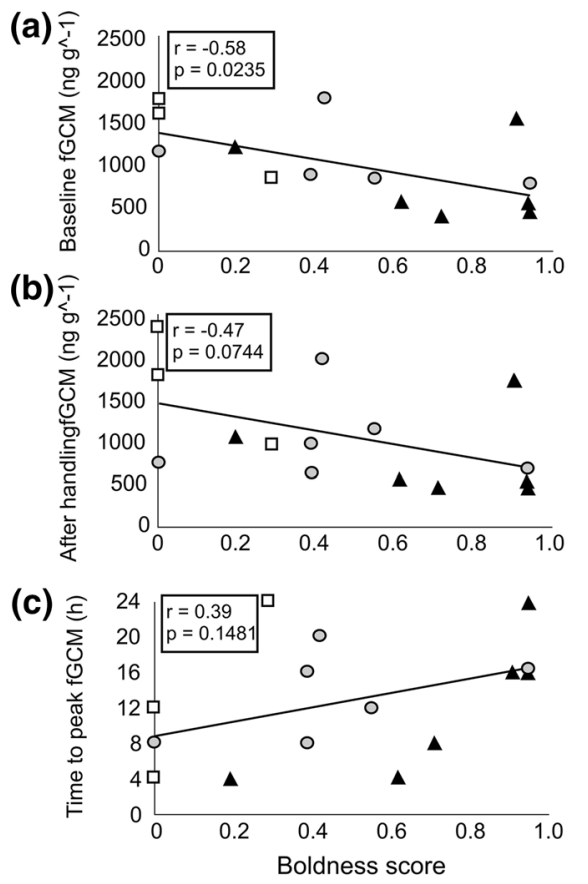

$\square$ Adult females $\boldsymbol{\Delta}$ Juvenile females O Juvenile males

Fig. 6 Correlations between boldness scores ("novel object" test) and mean baseline fGCM concentrations before handling (a, $n=15)$, mean fGCM concentrations following handling $(\mathbf{b}, n=15)$ and time to reach peak fGCM concentrations after handling $(\mathbf{c}, n=15)$ for adult female (white squares), juvenile female (black triangles) and juvenile male (grey circles) Arctic foxes (Vulpes lagopus)

suited for measuring adrenocortical activity in the Arctic fox. Fecal glucocorticoid metabolite concentrations increased compared to baseline levels following both the ACTH and the handling treatments. This confirms that this non-invasive method can be used to study adrenocortical activity in Arctic foxes.

Peak fGCM concentrations were found around $8-12 \mathrm{~h}$ (sampling interval 2-3) post treatment. This is comparable to reported times found in silver foxes (Hovland et al. 2017). However, others have found much longer delays ( $24 \mathrm{~h}$ to $48 \mathrm{~h}$ ), when dealing with crab-eating, bat-eared and island foxes (Paz et al. 2014; Le Roux et al. 2016; Kozlowski et al. 2020). Assessing delay times is an important part of a validation experiment, because they indicate when acute stressors are reflected in fGCM concentrations (Palme 2019). As gut passage time and defecation rate play a crucial role in fGCM concentrations, differences in available food and other factors may exert an influence on expected delay times and thus need to be taken into account when analyzing samples from wild Arctic foxes.

A recent study (McDonald et al. 2018) used a cortisol radioimmunoassay for measuring fGCMs in Arctic foxes. Despite adding extremely high amounts of cortisol to the fox diet, the measured fGCM levels were only moderately 
increased afterwards, suggesting that the applied cortisol radioimmunoassay may not be suitable for Arctic foxes. Based on our HPLC immunograms (and in accordance with the literature; see the supplementary tables in Palme 2019), cortisol itself is absent in the feces of Arctic foxes because it has metabolized into fGCMs. Thus, an immunoassay measuring groups of fGCMs should be favored over one measuring the parent hormone cortisol (Palme 2019). This is further underlined by the fact that we found a cortisol EIA unsuited to detect the increase in fGCMs after an ACTH challenge test (leading to physiological increases in plasma GC levels), but pronounced increases were found with a $5 \alpha$-pregnane-3ß,11ß,21-triol-20-one EIA which is designed to measure groups of fGCMs. This latter EIA could also detect smaller increases after handling alone. The same EIA proved also best suited for fGCM analysis in silver foxes (Hovland et al. 2017).

There were large variations in adrenocortical activity between individual foxes, but the differences could neither be attributed to their sex nor age. This is in line with a previous study in silver foxes (Hovland et al. 2017), but the low sample size, especially for adult females, limits our interpretations for the Arctic fox. Baseline fGCM concentrations were instead found to be negatively related to the boldness scores of the foxes, and concentrations following handling tended to show the same relationship. There was, however, no relationship between the increase in mean concentrations from baseline to handling and boldness score, showing that although shyer foxes did not respond stronger to the handling, they still had overall higher fGCM concentrations than the bolder foxes.

Because the bolder foxes had lower fGCM concentrations, and boldness and confidence scores tended to covary, our study suggest that foxes' adrenocortical activity may be connected to certain personality traits. This is in line with previous studies (reviewed by Koolhaas et al. 1999; Sapolsky et al. 2000; Carere et al. 2010) documenting relationships between personality and adrenocortical activity. Similar to our findings, more reactive (shy, less explorative, and less social) individuals of wild Eastern chipmunks (Tamias striatus) had higher cortisol levels compared to more proactive (bold, explorative and social) individuals (Martin and Réale 2008). Among other carnivores, farmed mink (Neovison vison) selected for less confident behaviors had stronger adrenocortical responses to handling compared to more confident mink (Malmkvist et al. 2003). The same relationship was found in clouded leopards (Neofelis nebulosi), where more anxious individuals had higher fGCM concentrations compared to calmer individuals (DeCaluwe et al. 2013). In grey wolves (Canis lupus), fGCMs were, however, not related to the personality trait investigated (aggressivity and agonism), but rather to the dominance relationship within the pack (Creel 2005). Arctic foxes can also live in social groups, but not with the same hierarchical relationship as wolves, which makes similar effects unlikely in the foxes (Norén et al. 2012). In farmed silver foxes, confidence towards humans was, contradictory to predictions based on previous literature (e.g. Sih et al. 2004), positively related to baseline fGCM concentrations (Hovland et al. 2017). In contrast, we found no relationship between fGCMs and confidence in the farmed Arctic foxes. These results suggest that, either, the relationship between confidence towards humans and fGCM concentrations may be more complex, or that there may be limits in the use of the "tit bit" test for measuring confidence towards humans. Furthermore, since the farmed foxes have close contact with humans on a daily basis, it is possible that the difference in confidence towards humans is lower compared to wild foxes. In wild Arctic foxes, bolder individuals have been found to tolerate closer approaches by a human observer before rising from lying down and fleeing or hiding, compared to shyer individuals (Choi et al. 2019). Higher tolerance to humans has also been seen in foxes inhabiting den sites close to trails and tourist mountain huts (Larm et al. 2020b), likely due to habituation. Although it may be difficult to differentiate between boldness and habituation in wild foxes, both could potentially affect adrenocortical responses. We will explore this in future studies by sampling captive wild foxes (from the captive breeding program) and wild foxes from different subpopulations.

Because it is often difficult to collect and freeze fecal samples from wild Arctic foxes directly following defecation, we investigated the stability of fGCM concentrations under different conditions. In the storage experiment we found no change in fGCM concentrations over the 48-h experimental period, either for the samples at $8-10{ }^{\circ} \mathrm{C}$ or at $20^{\circ} \mathrm{C}$. Experiments in capercaillie (Tetrao urogallus), in similar temperatures, also revealed no change in fGCM concentrations in samples stored at $8{ }^{\circ} \mathrm{C}$, even after 21 days. In samples stored at $21{ }^{\circ} \mathrm{C}$, however, no change was detected after 7 days, but after 21 days fGCM concentrations had increased significantly (Thiel et al. 2005). Other factors found to influence fGCM stability that are relevant for Arctic fox studies are rainfall and freeze-thaw cycles (Washburn and Millspaugh 2002). As ambient temperatures in Arctic fox habitats during winter are near or below $0{ }^{\circ} \mathrm{C}$, fecal sample collection during winter would be preferred as fGCM concentrations can be assumed to be relatively stable. For summer collection, however, considerations are needed as it is unknown how fGCM concentrations in the Arctic fox change over longer time periods and when exposed to various weather conditions. Thus, when higher temperatures occur, it will be important to freeze samples as soon as possible to prevent further possible changes in fGCMs after collection.

There was significant diurnal variation in the concentration of fGCMs, with generally higher concentrations in 
the feces collected during the day. The mean time to reach peak concentrations following treatment was approximately 10-12 $\mathrm{h}$, indicating that the adrenocortical activity was higher in the foxes during the night. That could be due to the fact that the Arctic fox is mostly nocturnal, using more energy during night (Thierry et al. 2020), with, thus, a corresponding increase in adrenocortical activity. There was however, large individual variation in the time to reach peak concentration, varying from $4 \mathrm{~h}$ to $24 \mathrm{~h}$. This difference could partly be explained by variation in metabolic rate. The minimum gut passage time of Arctic foxes is around $4 \mathrm{~h}$, but can be up to $24 \mathrm{~h}$ and even longer and may vary with different food and between individuals (Graae et al. 2004). Furthermore, the diurnal variation recorded for captive-bred and farm-raised foxes, may differ from the patterns seen in wild foxes, due to more irregular feeding, varied food items and resulting varied gut passage times.

In large parts of their range, Arctic foxes live in a highly fluctuating environment driven by the cyclic abundance of their main prey, small rodents. Glucocorticoid levels of small rodents fluctuate and may reach particularly high levels after a stressful event (Fauteux et al. 2017). Cyclicity in GC levels have also been found in snowshoe hares (Lepus americanus), depending on the phase of the cycle (Boonstra et al. 1998; Sheriff et al. 2011b). For studies of wild Arctic foxes living in fluctuating systems, it will be important to consider and investigate potential phase-effects on Arctic fox adrenocortical activity.

\section{Conclusions and recommendations for future studies in wild and captive Arctic foxes}

Here, we successfully validated the use of fecal glucocorticoid metabolites as an indicator of adrenocortical activity in the Arctic fox, thereby enabling future studies of stress responses in both wild and captive foxes. We found that fecal glucocorticoid metabolite (fGCM) concentrations remained stable over $48 \mathrm{~h}$ at both $8-10{ }^{\circ} \mathrm{C}$ and at $20^{\circ} \mathrm{C}$. This will enable more extensive studies of wild foxes in the field, where it may not always be possible to collect and freeze samples directly following defecation.

Variations in fGCMs could not be attributed to the sex or age of the foxes in this study, possibly due to the small sample size. However, given the relationship found between personality traits and fGCM concentrations, it would be valuable if fecal samples could be connected to individual foxes (e.g. DNA identification; Coppes et al. 2018). In addition, behavioral assessments should be an important component for interpretation of stress measurements, especially in foxes within the Norwegian captive breeding program. Habituation to human activities could potentially affect fGCM levels in both wild and captive Arctic foxes.

Due to significant diurnal variations found in this study, it would be preferable to collect feces defecated at approximately the same time of the day. However, this could be challenging in field situations, or if captive foxes are feed with carcasses with hair, skin and bone, as defecation rates in wild foxes likely vary from the patterns seen here, due to the irregularity of feeding and thus gut passage time in wild foxes compared to farm-raised foxes, which could make diurnal variations difficult to interpret.

Adrenocortical activity of the Arctic foxes may vary in relation to the phases of the small-rodent cycle, due to cyclic changes in abundance of rodent. We further expect that stress levels vary with population density, and hence physical condition, as well as varying presence of competitors and predators. This will be important to explore doing future studies in the wild. As the foxes in the Norwegian captive breeding and release program are held in large, open outdoor enclosures set directly on mountain habitat (elevation: 1275 m.a.s.l.; Landa et al. 2017) potential effects of small rodent cycles may apply to them as well.

In conclusion, analyzing fGCMs is an effective and non-invasive approach for studying adrenocortical activity. It can be used as a tool to optimize health/welfare and reproduction of Arctic foxes within captive breeding and release programs. However, it will prove useful to better understand the responses of wild Arctic foxes to various stressors, especially when combined with behavioral, demographic, and genetic studies.

Supplementary Information The online version contains supplementary material available at https://doi.org/10.1007/s00300-021-02917-1.

Acknowledgements We wish to thank Odd Niklas Haugrønning for allowing the experiment at his farm and for help during the experiment. We are also grateful to Kristine Ulvund and Roger Meås for help throughout the experiment and to Elisa Keeling Hemphill, Alexa Huber and Sonja Hartl for assistance in the lab. Mandy Keogh and two anonymous reviewers provided valuable suggestions regarding revision of the manuscript. The study was financed through the Scandinavian collaborative EU/InterReg-project Felles Fjellrev II (grant no. 20200939) and the ECOFUNC project funded by the Norwegian Research Council (grant no. 244557/E50).

Author contributions NEE, AL and AA conceived the study and NEE, ALH, AMT and ML designed the experiments. ML conducted the fecal collection and behavioral studies with help from veterinarian ALM for the ACTH injection. RP performed fGCM analysis in his lab. ML analyzed the data and wrote the manuscript with help from all co-authors. All authors read and approved the manuscript.

Funding Open access funding provided by Stockholm University. The study was financed through the Scandinavian collaborative EU/ InterReg-project Felles Fjellrev II (Grant No. 20200939) and the 
ECOFUNC project funded by the Norwegian Research Council (Grant No. 244557/E50).

Data availability The datasets generated during and/or analysed during the current study are available from the corresponding author upon reasonable request.

\section{Declarations}

Conflict of interest The authors declare that they have no conflict of interest.

Ethical approval The study was reviewed by the Norwegian Institute for Nature Research's animal welfare unit and approved by the Norwegian Food Safety Authority (Mattilsynet, FOTS identity no. 18734). The animals were held following regulations for the keeping of fur animals in Norway (Pelsdyrforskriften FOR-2011-03-17-296).

Open Access This article is licensed under a Creative Commons Attribution 4.0 International License, which permits use, sharing, adaptation, distribution and reproduction in any medium or format, as long as you give appropriate credit to the original author(s) and the source, provide a link to the Creative Commons licence, and indicate if changes were made. The images or other third party material in this article are included in the article's Creative Commons licence, unless indicated otherwise in a credit line to the material. If material is not included in the article's Creative Commons licence and your intended use is not permitted by statutory regulation or exceeds the permitted use, you will need to obtain permission directly from the copyright holder. To view a copy of this licence, visit http://creativecommons.org/licenses/by/4.0/.

\section{References}

Andersson A, Laikre L, Bergvall UA (2014) Two shades of boldness: novel object and anti-predator behavior reflect different personality dimensions in domestic rabbits. J Ethol 34:123-136. https:// doi.org/10.1007/s10164-014-0401-9

Angerbjörn A, Meijer T, Eide NE, Henttonen H, Norén K (2008) SEFALO report - Saving the endangered Fennoscandian Alopex lagopus. LIFE03 NAT/000073, Stockholm, Sweden

Angerbjörn A, Eide NE, Dalén L, Elmhagen B, Hellström P, Ims RA, Killengreen S, Landa A, Meijer T, Mela M, Niemimaa J, Norén K, Tannerfeldt M, Yoccoz NG, Henttonen H (2013) Carnivore conservation in practice: replicated management actions on a large spatial scale. J Appl Ecol 50:59-67. https://doi.org/10.1111/13652664.12033

Audet AM, Robbins CB, Larivière S (2002) Alopex Lagopus. Mammalian Species 713:1-10

Bates D, Märchler M, Bolker BM, Walker S (2015) Fitting linear mixed-effects models using lme4. J Stat Softw 67:1-48. https:// doi.org/10.18637/jss.v067.i01

Boonstra R, Hik D, Singleton GR, Tinnikov A (1998) The impact of predator-induced stress on the snowshoe hare cycle. Ecol Monogr 68:371-394. https://doi.org/10.1890/0012-9615(1998)068[0371: TIOPIS]2.0.CO;2

Carere C, Caramaschi D, Fawcett TW (2010) Covariation between personalities and individual differences in coping with stress: converging evidence and hypotheses. Curr Zool 56:728-740. https:// doi.org/10.1093/czoolo/56.6.728

Choi S, Grocutt E, Erlandsson R, Angerbjörn A (2019) Parent personality is linked to juvenile mortality and stress behavior in the arctic fox (Vulpes lagopus). Behav Ecol Sociobiol 73:162. https://doi. org/10.1007/s00265-019-2772-y

Coppes J, Kämmerle JL, Willert M, Kohnen A, Palme R, Braunisch V (2018) The importance of individual heterogeneity for interpreting fecal glucocorticoid metabolite levels in wildlife studies. J Appl Ecol 55:2043-2054. https://doi.org/10.1111/1365-2664.13140

Creel S (2005) Dominance, aggression and glucocorticoid levels in social carnivores. J Mammal 86:255-264. https://doi.org/10.1644/ BHE-002.1

DeCaluwe HB, Wielebnowski NC, Howard JG, Pelican KM, Ottinger MA (2013) Behavioral reactions relate to adrenal activity and temperament in male clouded leopards (Neofelis nebulosa). Appl Animl Behav Sci 149:63-71. https://doi.org/10.1016/j.applanim. 2013.09.008

Eide NE, Elmhagen B, Norén K, Killengreen ST, Wallén JF, Ulvund K, Landa A, Ims RA, Flagstad Ø, Ehrich D, Angerbjörn A (2017) Norwegian-Swedish action plan for the arctic fox (Vulpes lagopus), 2017-2021. Ministry of Environment in Norway, Report M-794. Available at: https://www.miljodirektoratet.no/globalasse ts/publikasjoner/M794/M794.pdf

Elmhagen E, Berteaux D, Burgess RM, Ehrich D, Gallant D, Henttonen H, Ims RA, Killengreen ST, Niemimaa J, Norén K, Ollila T, Rodnikova A, Sokolov AA, Sokolova NA, Stickney AA, Angerbjörn A (2017) Homage to Hersteinsson and Macdonald: climate warming and resource subsidies cause red fox range expansion and Arctic fox decline. Polar Res 36:3. https://doi.org/10.1080/ 17518369.2017.1319109

Fauteux D, Gauthier G, Berteaux D, Bosson C, Palme R, Boonstra R (2017) Assessing stress in arctic lemmings: fecal metabolite levels reflect plasma free corticosterone levels. Physiol Biochem Zool 90:370-382. https://doi.org/10.1086/691337

Gallant D, Lecomte N, Berteaux D (2019) Disentangling the relative influences of global drivers of change in biodiversity: a study of the twentieth-century red fox expansion into the Canadian Arctic. J Anim Ecol 2020(89):565-576. https://doi.org/10.1111/ 1365-2656.13090

Giese M (1998) Guidelines for people approaching breeding groups of Adelie penguins (Pygoscelis adeliae). Polar Rec 34:287-292. https://doi.org/10.1017/S0032247400025973

Gill JA, Norris K, Sutherland WJ (2001) Why behavioural responses may not reflect the population consequences of human disturbance. Bio Cons 97:265-268. https://doi.org/10.1016/S00063207(00)00002-1

Graae BJ, Pagh S, Bruun HH (2004) An experimental evaluation of the Arctic fox (Alopex lagopus) as a seed disperser. Arct Antarct Alp Res 36:468-473. https://doi.org/10.1657/1523-0430(2004) 036[0468:AEEOTA]2.0.CO;2

Haage M, Bergvall UA, Maran T, Kiik K, Angerbjörn A (2013) Situation and context impacts the expression of personality: The influence of breeding season and test context. Behav Process 100:103109. https://doi.org/10.1016/j.beproc.2013.08.009

Henriksen S, Hilmo, O (2015) The 2015 Norwegian red list for species. Norwegian Biodiversity Information Centre, Trondheim, Norway

Hersteinsson P, Macdonald DW (1992) Interspecific competition and the geographical distribution of red and Arctic foxes Vulpes vulpes and Alopex lagopus. Oikos 64(3):505-515. https://doi.org/10. $2307 / 3545168$

Hovland AL, Rød AMS, Eriksen MS, Palme R, Nordgreen J, Mason GJ (2017) Fecal cortisol metabolites as an indicator of adrenocortal activity in farmed silver foxes (Vulpes vulpes). Appl Anim Behav Sci 197:75-80. https://doi.org/10.1016/j.applanim.2017.08.009

Ims RA, Henden J-A, Killengreen ST (2008) Collapsing population cycles. Trends Ecol Evol 23:79-86. https://doi.org/10.1016/j.tree. 2007.10.010

Ims RA, Killengreen ST, Ehrich D, Flagstad Ø, Hamel S, Henden J-A, Jensvoll I, Yoccoz NG (2017) Ecosystem drivers of an arctic fox 
population at the western fringe of the Eurasian Arctic. Polar Res 36:8. https://doi.org/10.1080/17518369.2017.1323621

Kausrud KL, Mysterud A, Steen H, Vik JO, Østbye E, Cazelles B, Framstad E, Eikeset AM, Mysterud I, Solhøy T, Stenseth NC (2008) Linking climate change to lemming cycles. Nature 456:9397. https://doi.org/10.1038/nature07442

Kempe R, Koskinen N, Peura J, Koivula M, Strandén I (2009) Body condition scoring method for the blue fox (Alopex lagopus). Acta Agri Scand Sec A Anim Sci 59(2):85-89. https://doi.org/10.1080/ 09064700903045341

Killengreen ST, Ims RA, Yoccoz NG, Bråthen KA, Henden J-A, Schott $T$ (2007) Structural characteristics of a low Arctic tundra ecosystem and the retreat of the Arctic fox. Biol Conserv 135:459-472. https://doi.org/10.1016/j.biocon.2006.10.039

Koolhaas JM, Korte SM, De Boer SF, Van Der Vegt BJ, Van Reenen CG, Hopster H, De Jong IC, Ruis MAW, Blokhuis HJ (1999) Coping styles in animals: current status in behavior and stressphysiology. Neurosci Biobehav Rev 23:925-935. https://doi.org/ 10.1016/S0149-7634(99)00026-3

Kozlowski CP, Clawitter H, Guglielmino A, Schamel J, Baker S, Franklin AD, Powell D, Coonan TJ, Asa CS (2020) Factors affecting glucocorticoid and thyroid hormone production of island foxes. $\mathrm{J}$ Wildl Manage 84:505-514. https://doi.org/10.1002/jwmg.21808

Landa A, Flagstad Ø, Areskog V, Linell JDC, Strand O, Ulvund KR, Thierry AM, Rod-Eriksen L, Eide NE (2017) The endangered Arctic fox in Norway - the failure and success of captive breeding and reintroduction. Polar Res 36:9. https://doi.org/10.1080/17518 369.2017.1325139

Larm M, Elmhagen B, Granquist SM, Brundin E, Angerbjörn A (2018) The role of wildlife tourism in conservation of endangered species: implications of safari tourism for conservation of the Arctic fox in Sweden. Hum Dimens Wildl 23:257-272. https://doi.org/ 10.1080/10871209.2017.1414336

Larm M, Erlandsson R, Norén K, Angerbjörn A (2020a) Fitness effects of ecotourism on an endangered carnivore. Anim Conserv 23:386-395. https://doi.org/10.1111/acv.12548

Larm M, Brundin E, Stålhandske T, Angerbjörn A (2020b) Arctic fox responses to tourism activity. J Wildl Manage 84(4):821-828. https://doi.org/10.1002/jwmg.21827

Le Corre N, Gélinaud G, Brigand L (2009) Bird disturbance on conservation sites in Brittany (France): the standpoint of geographers. J Coast Conserv 13:109-118. https://doi.org/10.1007/ s11852-009-0057-8

le Roux A, Botha H, Dalerum F, Ganswindt A (2016) Non-invasive measurement of adrenocortical activity in a myrmecophageous mammal, the bat-eared fox. Afr Zool 51:47-51. https://doi.org/ 10.1080/15627020.2016.1145071

Lenth R, Singmann H, Love J, Buerkner P, Herve M (2019) R package emmeans: estimated marginal means, aka least-squares means. Available at https://cran.rproject.org/web/packages/emmeans.

MacDougall-Shackleton SA, Bonier F, Romero LM, Moore IT (2019) Glucocorticoids and "stress" are not synonymous. Integr Organism Biol 1:obz017. https://doi.org/10.1093/iob/obz017

Malmkvist J, Hansen SW, Damgaard BM (2003) Effects of the serotonin agonist buspirone on behavior and hypothalamic-pituitaryadrenal axis in confident and fearful mink. Physiol Behav 78:229240. https://doi.org/10.1016/S0031-9384(02)00964-2

Malmkvist J, Jeppesen LL, Palme R (2011) Stress and stereotypic behaviour in mink (Mustela vison): a focus on adrenocortical activity. Stress 14:312-323. https://doi.org/10.3109/10253890. 2010.547640

Martin JGA, Réale D (2008) Animal temperament and human disturbance: Implications for the response of wildlife to tourism. Behav Process 77:66-72. https://doi.org/10.1016/j.beproc.2007.06.004
Mason GJ (2010) Species differences in responses to captivity: stress, welfare and the comparative method. Trends Ecol Evol 25:71721. https://doi.org/10.1016/j.tree.2010.08.011

McDonald RS, Roth JD, Anderson WG (2018) Prey cortisol affects the usefulness of fecal glucocorticoid metabolite concentration as an indicator of stress in a carnivore. Can J Zool 96:367-371. https:// doi.org/10.1139/cjz-2017-0065

Monfort SL, Mashburn KL, Brewer BA, Creel SR (1998) Evaluating adrenal activity in African Wild Dogs (Lycaon pictus) by fecal corticosteroid analysis. J Zoo Wildlife Med 29:129-133

Möstl E, Palme R (2002) Hormones as indicators of stress. Domest Anim Endocrinol 23:67-74. https://doi.org/10.1016/S07397240(02)00146-7

Millspaugh JJ, Washburn BE (2004) Use of fecal glucocorticoid metabolite measures in conservation biology research: considerations for application and interpretation. Gen Comp Endocrinol 138:189-199. https://doi.org/10.1016/j.ygcen.2004.07.002

Norén K, Hersteinsson P, Samelius G, Eide NE, Fuglei E, Elmhagen B, Dalén L, Meijer T, Angerbjörn A (2012) From monogamy to complexity: social organization of arctic foxes (Vulpes lagopus) in contrasting ecosystems. Can J Zool 90:1102-1116. https://doi. org/10.1139/z2012-077

Palme R, Möstl E (1997) Measurement of cortisol metabolites in faeces of sheep as a parameter of cortisol concentration in blood. Z Saugetierkd 62(Suppl II):192-197

Palme R, Rettenbacher S, Touma C, El-Bahr SM, Möstl E (2005) Stress hormones in mammals and birds: Comparative aspects regarding metabolism, excretion and noninvasive measurement in fecal samples. Ann NY Acad Sci 1040:162-171. https://doi.org/10.1196/ annals.1327.021

Palme R, Touma C, Arias N, Dominchin MF, Lepschy M (2013) Steroid extraction: get the best out of fecal samples. Wien Tierarztl Monatsschr 100:238-246

Palme R (2019) Non-invasive measurement of glucocorticoids: advances and problems. Physiol Behav 199:229-243. https://doi. org/10.1016/j.physbeh.2018.11.021

Paz RCR, Souza NP, Brown JL (2014) Evaluation of glucocorticoid fecal monitoring as a non-invasive assessment of stress in captive crab-eating fox (Cerdocyoun thous) after ACTH stimulation. J Steroids Horm Sci S 12:008. https://doi.org/10.4172/2157-7536. S12-008

R Core Team (2019) R: a language and environment for statistical computing. R Foundation for Statistical Computing, Vienna, Austria. Available at https://www.R-project.org/

R Studio (2019) R Studio. Version 1.2.5033 [computer program]. R Studio, Boston, Massachusetts, USA. Available at https://www. rstudio.com/products/rstudio/

Réale D, Reader SM, Sol D, McDougall PT, Dingemanse NJ (2007) Integrating animal temperament within ecology and evolution. Biol Rev 82:291-318. https://doi.org/10.1111/j.1469-185X.2007. 00010.x

Reeder D-AM, Kramer KM (2005) Stress in free-ranging mammals: integrating physiology, ecology, and natural history. J Mammal 86:225-235. https://doi.org/10.1644/BHE-003.1

Rekilä T, Harri M, Ahola L (1997) Validation of the feeding test as an index of fear in farmed blue (Alopex lagopus) and Silver foxes (Vulpes vulpes). Physiol Behav 62:805-810. https://doi.org/10. 1016/S0031-9384(97)00241-2

Sanson G, Brown JL, Farstad W (2005) Non-invasive fecal steroid monitoring of ovarian and adrenal activity in farmed blue fox (Alopex lagopus) females during late pregnancy, parturition and lactation onset. Anim Reprod Sci 87:309-319. https://doi.org/10. 1016/j.anireprosci.2004.12.001

Sapolsky RM, Romero LM, Munck AU (2000) How do glucocorticoids influence stress responses? integrating permissive, suppressive, 
stimulatory, and preparative actions. Endocr Rev 21:55-89. https://doi.org/10.1210/edrv.21.1.0389

Schatz S, Palme R (2001) Measurement of fecal cortisol metabolites in cats and dogs: a non-invasive method for evaluating adrenocortical function. Vet Res Commun 25:271-287. https://doi.org/10. 1023/A:1010626608498

Sheriff MJ, Dantzer B, Delehanty B, Palme R, Boonstra R (2011a) Measuring stress in wildlife: techniques for quantifying glucocorticoids. Oecologia 166:869-887. https://doi.org/10.1007/ s00442-011-1943-y

Sheriff MJ, Krebs CJ, Boonstra R (2011b) From process to pattern: how fluctuating predation risk impacts the stress axis of snowshoe hares during the 10-year cycle. Oecologia 166:593-605. https:// doi.org/10.1007/s00442-011-1907-2

Shutt K, Heistermann M, Kasim A, Todd A, Kalousova B, Profosouva I, Petrzelkova K, Fuh T, Dicky J-F, Bopalanzognako J-B, Setchell JM (2014) Effects of habituation, research and ecotourism on fecal glucocorticoid metabolites in wild western lowland gorillas: implications for conservation management. Biol Conserv 172:72-79. https://doi.org/10.1016/j.biocon.2014.02.014

Sih A, Bell AM, Johnson JC, Ziemba RE (2004) Behavioral syndromes: an integrative overview. Q Rev Biol 79:241-277

SMHI (2020) Normal mean temperatures in Sweden in July and August (In Swedish). Available at: https://www.smhi.se/data/meteorologi/ kartor/normal-manadsmedeltemperatur/manad/juli and https:// www.smhi.se/data/meteorologi/kartor/normal-manadsmedeltemp eratur/manad/augusti. Accessed10 Mar 2020.

Sokolov AA, Sokolova NA, Ims RA, Brucker L, Ehrich D (2016) Emergent rainy winter warm spells may promote boreal predator expansion into the Arctic. Arctic 69(2):121-129. https://doi.org/ 10.14430/arctic4559

Sosa S, Dobson FS, Bordier C, Neuhaus P, Saraux C, Bosson C, Viblanc VA (2020) Social stress in female Columbian ground squirrels: density-independent effects of kin contribute to variation in fecal glucocorticoid metabolites. Behav Ecol Sociobiol 74:50. https://doi.org/10.1007/s00265-020-02830-3

Steinman KJ, Robeck TR (2021) Establishing models of corticosteroid patterns during the life history of killer whales (Orcinus orca) under human care. Gen Comp Endocrinol 301:113664. https:// doi.org/10.1016/j.ygcen.2020.113664
Thiel D, Jenni-Eiermann S, Palme R (2005) Measuring corticosterone metabolites in droppings of Capercaillies (Tetrao urogallus). Ann NY Acad Sci 1046:96-108. https://doi.org/10.1196/annals. 1343.009

Thierry AM, De Lacoste NB, Ulvund K, Andersen R, Meås R, Eide NE, Landa A (2020) Use of supplementary feeding dispensers by Arctic fox in Norway. J Wildl Manage 84(4):622-635. https://doi. org/10.1002/jwmg.21831

Tirronen K, Ehrich D, Panchenko D, Dalén L, Angerbjörn A (2021) The Arctic fox (Vulpes lagopus L.) on the Kola Peninsula (Russia): silently disappearing in the mist of data deficiency? Polar Biol (in press). https://doi.org/10.1007/s00300-021-02847-y

Touma C, Palme R (2005) Measuring fecal glucocorticoid metabolites in mammals and birds: the importance of validation. Ann NY Acad Sci 1046:54-74. https://doi.org/10.1196/annals.1343.006

Touma C, Sachser N, Möstl E, Palme R (2003) Effects of sex and time of day on metabolism and excretion of corticosterone in urine and faeces of mice. Gen Comp Endocrinol 130:267-278. https://doi. org/10.1016/s0016-6480(02)00620-2

Villiers MS, Cooper J, Ryan PG (2005) Individual variability of behavioural responses by wandering albatrosses (Diomedea exulans) to human disturbance. Polar Biol 28:255-260. https://doi.org/10. 1016/S0016-6480(02)00056-4

Washburn BE, Millspaugh JJ (2002) Effects of simulated environmental conditions on glucocorticoid metabolite measurements in white-tailed deer feces. Gen Comp Endocrinol 127:217-222. https://doi.org/10.1016/S0016-6480(02)00056-4

Young KM, Walker SL, Lanthier C, Waddell WT, Monfort SL, Brown JL (2004) Noninvasive monitoring of adrenocortical activity in carnivores by fecal glucocorticoid analyses. Gen Comp Endocrinol 137:148-165. https://doi.org/10.1016/j.ygcen.2004.02.016

Publisher's Note Springer Nature remains neutral with regard to jurisdictional claims in published maps and institutional affiliations. 